\title{
A protocol for a cluster randomized trial comparing strategies for translating self-management support into primary care practices
}

W. Perry Dickinson ${ }^{1 *}$ D, L. Miriam Dickinson ${ }^{1}$, Bonnie T. Jortberg ${ }^{1}$, Danielle M. Hessler ${ }^{2}$, Douglas H. Fernald ${ }^{1}$ and Lawrence Fisher ${ }^{2}$

\begin{abstract}
Background: Advanced primary care models emphasize patient-centered care, including self-management support (SMS), but the effective use of SMS for patients with type 2 diabetes (T2DM) remains a challenge. Interactive behavior-change technology (IBCT) can facilitate the adoption of SMS interventions. To meet the need for effective SMS intervention, we have developed Connection to Health (CTH), a comprehensive, evidence-based SMS program that enhances interactions between primary care clinicians and patients to resolve self-management problems and improve outcomes. Uptake and maintenance of programs such as CTH in primary care have been limited by the inability of practices to adapt and implement program components into their culture, patient flow, and work processes. Practice facilitation has been shown to be effective in helping practices make the changes required for optimal program implementation. The proposed research is designed to promote the translation of SMS into primary care practices for patients with T2DM by combining two promising lines of research, specifically, (a) testing the effectiveness of $\mathrm{CTH}$ in diverse primary-care practices, and (b) evaluating the impact of practice facilitation to enhance implementation of the intervention.
\end{abstract}

Methods: A three-arm, cluster-randomized trial will evaluate three discrete strategies for implementing SMS for patients with T2DM in diverse primary care practices. Practices will be randomly assigned to receive and implement the $\mathrm{CTH}$ program, the $\mathrm{CTH}$ program plus practice facilitation, or a SMS academic detailing educational intervention. Through this design, we will compare the effectiveness, adoption and implementation of these three SMS practice implementation strategies. Primary effectiveness outcomes including lab values and evidence of SMS will be abstracted from medical records covering baseline through 18 months post-baseline. Data from CTH assessments and action plans completed by patients enrolled in CTH will be used to evaluate practice implementation of CTH and the impact of $\mathrm{CTH}$ participation. Qualitative data including field notes from encounters with the practices and interviews of practice personnel will be analyzed to assess practice implementation of SMS.

Discussion: This study will provide important information on the implementation of SMS in primary care, the effectiveness of an IBCT tool such as CTH, and the use of practice facilitation to assist implementation.

Trial registration: Registered with ClinicalTrials.gov - ClinicalTrials.gov ID: NCT01945918, date 08/27/2013. Modifications have been updated.

Keywords: Primary care, Type 2 diabetes mellitus, Practice facilitation, Self-management support, Patient-centered medical home, Psychosocial factors, Interactive technology

\footnotetext{
* Correspondence: perry.dickinson@ucdenver.edu

'Department of Family Medicine, University of Colorado School of Medicine,

12631 E. 17th Ave., Mail Stop F496, Aurora, CO 80045-0508, USA

Full list of author information is available at the end of the article
}

(c) The Author(s). 2018 Open Access This article is distributed under the terms of the Creative Commons Attribution 4.0 International License (http://creativecommons.org/licenses/by/4.0/), which permits unrestricted use, distribution, and

reproduction in any medium, provided you give appropriate credit to the original author(s) and the source, provide a link to the Creative Commons license, and indicate if changes were made. The Creative Commons Public Domain Dedication waiver (http://creativecommons.org/publicdomain/zero/1.0/) applies to the data made available in this article, unless otherwise stated. 


\section{Background}

Most patients with type 2 diabetes mellitus (T2DM) in the U.S. receive diabetes care in primary care settings, which are undergoing rapid transformations due to the need to improve quality and decrease costs. The Patient Centered Medical Home (PCMH) and the Chronic Care Model (CCM) are complementary clinical intervention frameworks that are commonly employed to support better T2DM outcomes in primary care [1-7]. Self-management Support (SMS) is a core component of both the PCMH and CCM, and focuses on the central role of patients in managing their illness by engaging with and adopting healthy behaviors that promote optimal clinical outcomes [6, 8-10]. SMS typically targets improvements in medication adherence, diet, exercise, and other risk-related behaviors; all of which are crucial for maintaining good glycemic control and reducing the risks of diabetes-related complications. Despite its recognized importance, SMS programs for diabetes continue to demonstrate limited effectiveness and sustainability in the real world of primary care [11, 12]. Primary-care physicians have been unable to comprehensively and consistently address diabetes self-management within an efficient and systematic SMS framework for several interrelated reasons: they are often overwhelmed by competing demands, poorly trained in assessing and intervening with health behavior change, lack practice systems for implementing change and quality improvement, and receive inadequate reimbursement for time spent in SMS activities [13-16].

Few tools are available to assist practices with self-management support. Interactive behavior-change technology (IBCT) can facilitate the adoption of crucial SMS interventions in primary care for patients with diabetes and related health risk behaviors [17-20]. Compared with traditional, unstructured programs, technological options for delivery have the advantage of increased convenience and accessibility, and may provide individualized support and resources necessary for initiating and maintaining healthful lifestyles, especially when they include non-automated options to address patient preference and permit patient tailoring [19-22] There is strong evidence that Internet-based programs can effectively promote health behaviors to support diabetes self-management, [23] such as healthful eating/ weight management, [24-27] increasing physical activity, [28-30] reducing depression symptoms, and smoking cessation [31, 32]. Multiple randomized trials have been conducted using IBCT programs for diabetes self-management with positive results [33, 34]. However, most current IBCT self-management programs contain several limitations to translation into primary care settings: [35, 36] they are largely informational, they require high literacy, they are limited to simple health-risk assessment without goal setting, action planning or follow-up, they fail to provide physician decision support, and they do not emphasize patient-physician collaboration. Furthermore, most are exclusively automated and do not take into account the preference of many patients and clinicians for different modes of assessment and intervention.

Connection to Health $(\mathrm{CTH})$ is a comprehensive, evidence-based SMS program that supports behavior change through IBCT. The CTH logic model is informed by social-cognitive [37-39] and social-ecological [40-42] theories and is inclusive of the evidence based principles for implementing SMS in primary care [43]. Multiple intervention components work together to promote enhanced, tailored diabetes management, which is linked to positive health outcomes [44-46]. Patients complete a CTH assessment that covers multiple issues related to diabetes and co-morbid conditions using state-of-the-art measures, each with cut-points defining a flagged area for concern. Patients receive an immediate summary, along with profiles from prior assessments to denote change over time. Patients are asked to review the summary and identify areas to discuss with their care team in preparation for making an action plan. A parallel report is prepared for the clinician that also includes decision support tools and options for the clinician for each flagged area on the profile, all to assist in beginning a conversation with the patient about specific problems and how they might be addressed. Action planning plays a central role, and includes goal setting and problem solving [47] through an automated, web-based action planning program. CTH also includes patient resources and tips to improve diabetes management. $\mathrm{CTH}$ is avehicle for structuring and guiding a time-effective clinical conversation between patient and the care team, enabling clinicians and patients to regularly assess, monitor, and intervene with self-management issues using a patient-centered approach that allows for practice and patient tailoring and encourages patient/ care team interaction.

The simple availability of effective IBCT tools like CTH does not assure their successful implementation $[15,16,48-50]$. Primary care practices are experiencing multiple pressures to see a large number of patients, to provide improved care, and to do so with very constrained reimbursement. Practices have few mechanisms to integrate new programs into routine care, which can exert major pressures on practice operations - even small changes can have substantial consequences that limit their effectiveness and sustainability [15, 16, 4850]. Adoption and implementation of new care programs varies across practices based on practice characteristics, including practice culture and change capacity, practice 
size, location (rural vs. urban), previous change experience, and decision-making style [13, 14, 51].

Practice facilitation has been effective in assisting practices in implementing organizational changes such the CCM and PCMH [52-58]. A facilitator can assist a practice in tailoring a new program to fit their unique practice situation, resources, and culture, improving its implementation and its sustainability over time. Practice facilitators use a motivational interviewing approach in assessing and increasing key stakeholders' motivation for change. The practice facilitation intervention impacts the practice's capacity for change through forming a quality improvement team, [59] training the team in quality improvement techniques including the use of Plan-Do-Study-Act (PDSA) for rapid cycle change, planning and implementing work flow and other changes, and identifying and working to overcome barriers. The quality improvement team consists of a diverse group of representatives from the various clinician and staff roles in the practice and meets regularly to plan the adoption and implementation of programs like $\mathrm{CTH}$.

This study has been designed to promote the translation of SMS into primary care practices for patients with
T2DM by combining two promising lines of research; specifically, testing the effectiveness of $\mathrm{CTH}$ for patients with T2DM in diverse primary care practices and evaluating the impact of practice facilitation to enhance uptake and maintenance of the intervention. Our specific aims for this project are:

1. To conduct a cluster randomized trial to examine the reach, effectiveness, adoption, implementation, and maintenance (RE-AIM) of CTH for patients with T2DM in primary care practices.

2. To determine the incremental benefit of brief targeted practice facilitation on the implementation of $\mathrm{CTH}$ in diverse primary care practices.

3. To identify key practice characteristics (e.g., practice size, organization, setting, and level of experience with practice redesign efforts) that affect CTH RE-AIM outcomes.

\section{Methods}

\section{Design}

To address these aims, we will undertake a three-arm, cluster-randomized trial to evaluate the reach, effectiveness, adoption, implementation, and maintenance of

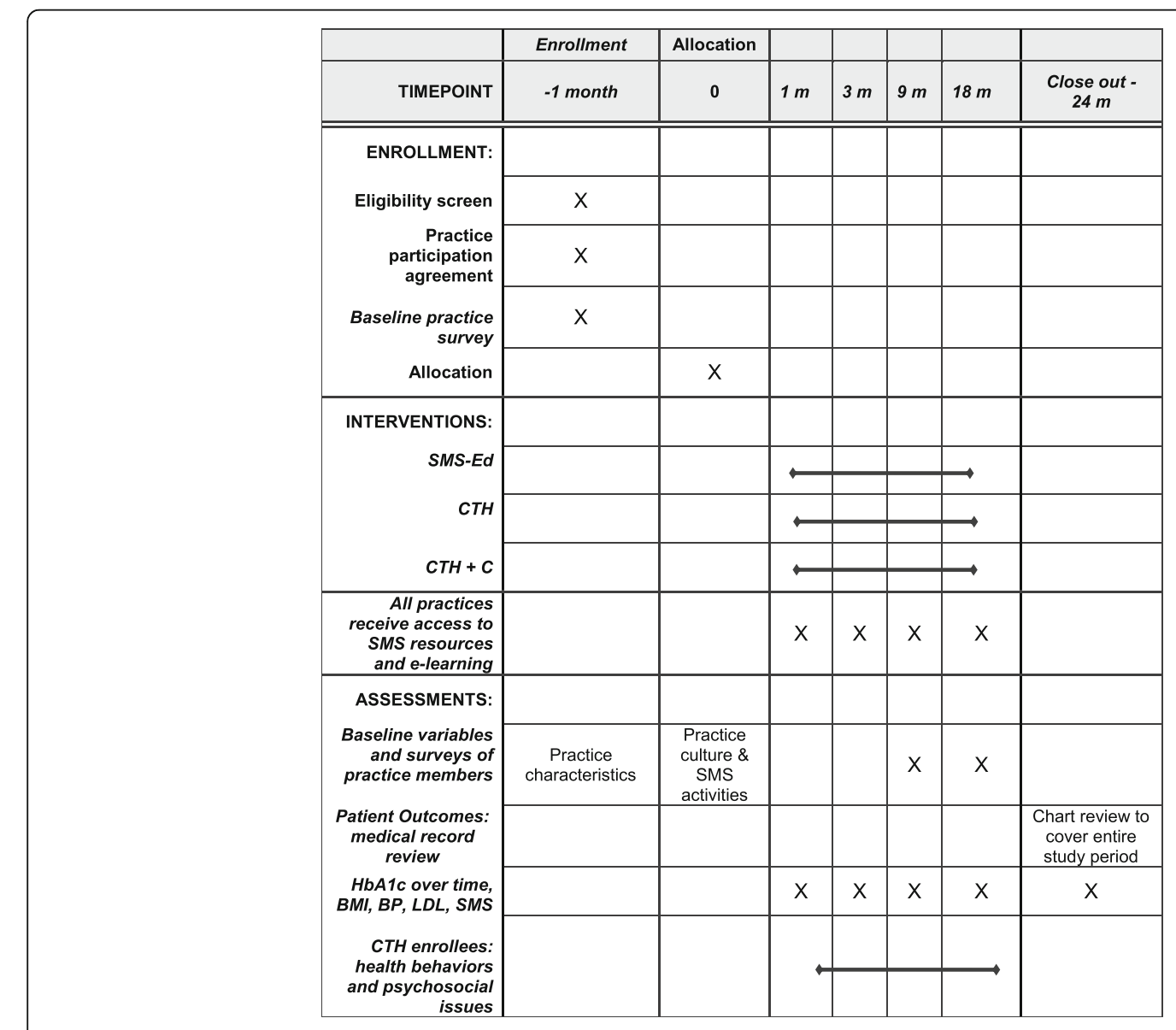

Fig. 1 Timing of Enrollment, Interventions, and Assessments 
$\mathrm{CTH}$ for patients with T2DM in diverse primary care practices (Fig. 1). Primary care practices will be randomly assigned to receive and implement the CTH program $(\mathrm{CTH})$, the $\mathrm{CTH}$ program plus practice facilitation $(\mathrm{CTH}+\mathrm{F})$, or an SMS academic detailing educational intervention (SMS-Ed). Through this design, we will compare the effectiveness, adoption and implementation of these three SMS practice implementation strategies. To assure maximum generalizability, we will recruit a diverse group of practices in Colorado and California. We have chosen this design in order to examine the incremental effect of both CTH (CTH vs. SMS-Ed) and practice facilitation $(\mathrm{CTH}$ vs. $\mathrm{CTH}+\mathrm{F})$ on SMS outcomes, compared to an academic detailing educational intervention. Blinding of practice participants or study team is not possible.

\section{Sample}

We will recruit 36 primary care practices, 18 each in Colorado and California in the United States, with equal numbers randomized to each of the three arms in each state. Inclusion criteria are family medicine or general internal medicine practices with a minimum of 80 patients with T2DM, with all clinicians agreeing to participate. We will recruit a diverse set of practices of various sizes and organizational structures (such as private, system-owned, and safety net practices, date of first enrolment 11/14/2013). Balanced study arms are essential to the success of cluster randomized trials. Imbalanced study arms can adversely affect study interpretability and potentially weaken causal inference [60-63].

Covariate constrained randomization procedures have been demonstrated $[64,65]$ to be effective for ensuring acceptable study arm balance in cluster randomized trials. Using this procedure, all possible randomizations will first be generated within each stratum (Colorado or California). Next, standardized baseline variables for all clusters will be used to compute a balance criterion, which is the sum of squared differences between treatment arms across all selected variables; the balance score is a measure of the difference between study arms, so low scores reflect less difference. For this three-arm trial, three balance scores will be computed for each randomization (arm 1 vs. 2 , arm 2 vs. 3 , and arm 1 vs. $3)$. The distributions of balance scores will be examined and a cutoff of the 25th percentile for all three will be used as a criterion for identifying the "optimal set." From this set, a single randomization will be randomly selected using a random number generator and practices assigned to study arms by the project biostatistician.

\section{Interventions (see Table 1 and Fig. 1) SMS education (SMS-Ed) arm}

The SMS-ED arm serves as an attention control. Project staff will meet onsite with practice clinicians and staff members for two one-hour sessions to discuss what SMS is, why it is important, how primary care plays a role in this process, how others have approached it, and how it can be time and cost efficient for them to engage in SMS as part of standard diabetes care. Practices will have access to a website displaying general and local SMS resources, but will not have access to the formal CTH program. During this session, discussion of the implementation of these resources into the practice will be facilitated. No input will be provided regarding how unique practice characteristics might be utilized for more effective implementation of SMS, and CTH will not be introduced. Practices will be left to utilize these resources and to expand SMS activities as they see fit, without any further study input.

\section{Connection to Health (CTH) arm}

Practices in this arm will receive instruction in the use of the full CTH program, including web-based resources, but will not receive any practice facilitation to assist with adoption and implementation. The number

Table 1 Program Elements across Project Arms

\begin{tabular}{|c|c|c|c|}
\hline Program Element & SMS-Ed & $\mathrm{CTH}$ & $\overline{\mathrm{CTH}+\mathrm{F}}$ \\
\hline Connection to Health computerized intervention program & No & Yes & Yes \\
\hline Technical assistance with CTH implementation & No & Yes & Yes \\
\hline Basic instructions on use of $\mathrm{CTH}$ & No & Yes & Yes \\
\hline Assessment of baseline SMS and diabetes care activities & Yes & Yes & Yes \\
\hline Feedback of assessment and recommendations for practice & No & No & Yes \\
\hline Generic SMS education & Yes & Yes & Yes \\
\hline Generic website with SMS resources & Yes & Yes & Yes \\
\hline $\begin{array}{l}\text { Practice facilitation: } \\
\text { - Improvement team meetings - } 4 \text { over approximately } 3 \text { mos. } \\
\text { - Workflow revision to implement CTH } \\
\text { - Email contacts, other assistance between improvement team meetings and after } 3 \text { months as needed } \\
\text { - Ongoing feedback of data regarding CTH usage }\end{array}$ & No & No & Yes \\
\hline
\end{tabular}


and length of visits to these practices will be the same as for the SMS Education Arm, plus an additional one-hour training session on the technical aspects of $\mathrm{CTH}$. The content of the visits will center on the use of $\mathrm{CTH}$ as a way to implement SMS. Clinicians and selected staff members will be given hands-on experience using the system and will be provided with scenarios that will highlight the effective use of $\mathrm{CTH}$ as a tool for diabetes SMS. The practices will then implement $\mathrm{CTH}$ on their own, with additional technical assistance provided as needed.

\section{Connection to Health plus facilitation $(C T H+F)$ arm}

This arm includes the same three one-hour training sessions as $\mathrm{CTH}$, but adds short-term, focused practice facilitation. The active practice facilitation phase includes four meetings of the practice improvement team, scheduled for approximately $60 \mathrm{~min}$ each. The improvement team will consist of diverse representatives (generally 610) of the practice. The facilitator will assist the team in developing a $\mathrm{CTH}$ adoption plan and then help them identify small goals for rapid cycle change using the Plan-Do-Study-Act QI model. Active facilitation will last for approximately 3 months, followed by monthly calls by the facilitator to review data regarding the practice's use of CTH. A brief "booster" facilitation can also be scheduled to address subsequent problems.

\section{Patient samples}

\section{Patient population perspective}

Since allocation of patients occurs at the level of the practice in this trial, all patients within a practice will be assigned to the same treatment condition, regardless of the extent to which the individual patient uses the tools provided. Although the intervention can potentially impact the entire population of patients with T2DM, each practice in the $\mathrm{CTH}$ and $\mathrm{CTH}+\mathrm{F}$ arms will selectively utilize CTH with patients, and some patients introduced to $\mathrm{CTH}$ in a practice will follow through with it while others will not. Therefore, practices in each of the two arms with CTH will have patients who were and were not exposed to $\mathrm{CTH}$. To preserve intent-to-treat approaches and alleviate potential selection bias at the level of individual patient recruitment, [66-69] we will evaluate the effect of $\mathrm{CTH}$ by defining two overlapping patient samples in each practice. The first will be a random sample of all patients with type 2 diabetes mellitus, ages 21 and over diagnosed for a minimum of 12 months, whether or not they participated in $\mathrm{CTH}$ - the "Evaluation Sample." This sample will enable us to examine the effectiveness of the intervention on the primary outcome variables in the intent-to-treat analyses. A second sample in each practice will be comprised of only those patients with diabetes who complete the $\mathrm{CTH}$ assessment - the "CTH Sample." This sample will be used in "as treated" (per protocol) analyses. It should be noted that these two samples are not independent of each other; e.g., many in the CTH sample will be included randomly in the Evaluation Sample. Each sample, however, will be utilized to address different research questions.

\section{Evaluation sample}

Medical record reviews will be conducted on a random sample of patient who had received care in each practice for at least 1 year at baseline. Reviews will be conducted by research staff separate from the intervention team. The evaluator will be provided with a manual containing detailed instructions and will keep an audit log. A four-part data quality monitoring procedure will be employed consisting of use of a standardized abstraction protocol, extensive training in data abstraction, monitoring of Kappa values between the abstractors, and continuous quality improvement including periodic feedback to abstractors [70].

\section{CTH sample}

In addition to the evaluation sample described above, data from online $\mathrm{CTH}$ assessments, completed by those patients enrolled in $\mathrm{CTH}$, will be used to evaluate the level of implementation of $\mathrm{CTH}$ in practices as well as the impact of CTH participation on patient SMS outcomes. The combined samples will result in medical record reviews on up to 1800 patients.

Overall, this study involves no greater than minimal risk to practice member participants or patients. The primary risk is loss of confidentiality. Chart audits are completed on site within the practice and no identifying patient information is removed from the practice. Practice member surveys are anonymous, and we only retain practice (not individual) identifying information. Data are reported only in aggregate. Procedures for minimizing risk are in place and any breeches reported to the governing IRB. Field notes from practice facilitators are monitored regularly by the study team for monitoring trial conduct and possible adverse events.

\section{RE-AIM evaluation}

We will use the RE-AIM framework to guide our evaluation [71-77].

Reach will be assessed by comparing the percentage of eligible T2DM patients for whom there is evidence on chart review that SMS was provided by the practice across the three arms. The reach of the use of $\mathrm{CTH}$ will be assessed in two ways in the $\mathrm{CTH}$ and $\mathrm{CTH}+\mathrm{F}$ practices: (1) the percent of eligible T2DM patients with whom $\mathrm{CTH}$ is used by the practice (number of eligible T2DM patients enrolled in $\mathrm{CTH} /$ total number of eligible T2DM patients with diabetes in the practice), 
and (2) comparisons of patients who use CTH vs. patients who do not participate in $\mathrm{CTH}$ on the basis of key demographic and medical history information.

Effectiveness will be measured in intent-to-treat analyses by several sets of outcome variables collected from the evaluation sample by medical record review. Additionally, evaluation of patient-level "as treated" effects of participation in CTH will be carried out by comparing outcomes for patients enrolled in $\mathrm{CTH}$ to those not enrolled on all measures common to CTH.

Adoption will be assessed by the participation and representativeness of practices recruited for the study.

Implementation will be assessed by (a) the extent to which various intervention components are delivered to participants compared to intervention protocol; (b) description of practice-specific modifications to the basic protocol that seem to be effective; and (c) $\mathrm{CTH}$ website usage data.

Maintenance of the CTH system will be assessed by the extent of continued patient use of the CTH system over the intervention period, as well as the percent of practices at the 18-month follow-up continue using the CTH program.

\section{Measures}

\section{Primary Effectiveness Outcomes}

Will be obtained from the evaluation sample. HbA1c, LDL, systolic and diastolic blood pressure, and BMI will be abstracted from medical record reviews covering baseline through 18 months post-baseline. For each, the last measure prior to baseline will be used as the baseline measure.

\section{Practice SMS: Process of care}

The following elements will be assessed in medical record review: presence of a personal care plan with regular updating, evidence of collaborative goal setting, evidence of action planning around prioritized patient goals, evidence of collaborative problem-solving regarding the action planning process, use of community resources to assist in goal attainment, and evidence of ongoing monitoring of progress on identified goals. The chart audit form is available from the authors.

\section{Practice Characteristics}

Key practice characteristics will be used as covariates and potential moderators in analyses. Practice characteristics will be collected during the practice recruitment process, including level of quality improvement experience, level of $\mathrm{PCMH}$ implementation, practice size, setting (rural/urban), level/type of practice organization, baseline performance characteristics related to diabetes, percentage of minority patients in the practice, and percentage of Medicaid or uninsured patients. Additionally, practice members will be surveyed at baseline, 9, and 18 months to assess their perceptions of practice culture and provision of SMS to patients. Providers and staff who participate in surveys receive an information sheet explaining the evaluation purposes and procedures, and completion of the survey provided implied consent. Practice members included for interviews are provided with information by the study team and verbal consent obtained prior to proceeding with the interviews. Waiver of documentation of consent has been approved by the Institutional Review Boards.

\section{Secondary effectiveness outcomes from the $\mathrm{CTH}$ assessment} Congruent with policy recommendations from the Society of Behavioral Medicine, [78] we use brief scales that are reliable, sensitive to change, and age appropriate in the CTH assessment [79]. These include: diet (intake of saturated fat, fruits and vegetables, salt, and sweetened beverages); [80-82] physical activity (frequency and duration of participation in vigorous, moderate, and walking activity, as well as "screen" time from the International Physical Activity Questionnaire); [83] medication adherence (number of days missed, reasons for missing); [84-86] alcohol intake (number of drinks in past week, number of times imbibed more than limit in past month); $[87,88]$ tobacco use (whether or not using tobacco, if so, how much;) $[89,90]$ depression (PHQ-8); [91, 92] and disease-related distress (modified from the Diabetes Distress Scale) [93, 94]. For patients who complete the $\mathrm{CTH}$ assessment more than once, we will be able to compare the results over time. For patients who only complete it once over the study period, we will use the data to help describe the sample of patients with whom the practices used $\mathrm{CTH}$.

\section{Data management}

Standardized surveys and chart audit data collection tools and protocols with double data entry for paper forms are used throughout the project. Practice member surveys are administered at initial engagement with practice facilitation. Practice staff and clinicians could complete the survey either via paper copy or through an email link to REDCap. REDCap (Research Electronic Data Capture) is a secure, web-based application designed to support data capture for research studies. (REDCap is supported by supported by NIH/NCRR Colorado CTSI Grant Number UL1 RR025780.) Surveys are anonymous and no individual information was obtained. Data cleaning and coding are supervised by the project statistician. All core study team members will have access to the final dataset. 


\section{Power and sample size}

For the evaluation sample, chart audits of 30 patients per practice will yield 360 patients per arm (1080 total). Assuming an intraclass correlation (ICC) of $1 \%$, this sample size will provide $>80 \%$ power to detect a .25 SD difference between any two arms at follow-up or a medium linear trend effect $[95,96]$. In a related study the SD for HbA1c was 1.7 and the ICC for patients within practice was $<1 \%$. Thus, a .25 SD difference would translate to a final HbA1c difference of 0.43 between any two arms, adjusted for baseline differences. A similar effect size difference in systolic and diastolic blood pressure, LDL (all ICCs $<1$ ) would translate to a final difference of $4.5 \mathrm{mmHg}$ for systolic BP, 3.0 for diastolic BP, 8.8 for LDL.

\section{Quantitative data analysis}

For this cluster randomized trial, descriptive statistics will be computed for baseline patient and practice characteristics, initially testing for differences between: (1) different intervention arms and (2) CTH participants vs. non-participants. Patient-level covariates will be screened in bivariate analyses and included in multivariate analysis if they are related to the outcome at $p<.2$, differ between treatment arms, or are associated with dropout. In general, we will employ methods that utilize all available data, assuming ignorable missingness [97-100]. In the event normality assumptions are not met, we will use transformations to normalize distributions, ordinal or Poisson regression where appropriate, and/or the appropriate link function (e.g. logit link for dichotomized measures) [101-103]. We will employ intent to treat analyses using general (generalized) linear mixed models to incorporate data structures that are both hierarchical and longitudinal [66$69,102,104]$. Hypothesis tests will be two-sided with alpha $=.05$ or $p$ values reported. Goodness of fit statistics and model fitting diagnostics will be used to assess for influential points, outliers, overdispersion and heteroscedasticity and to evaluate alternative model specifications [101]. All statistical analyses will be performed using SAS version 9.2 (SAS Institute Inc., Cary, N.C.).

\section{Qualitative data collection and analysis}

Extensive qualitative data will be collected across the practices, including observational field notes and in-depth interviews done at baseline and at nine and 18 months from baseline. Field notes will be prepared by the facilitator and/or research staff after each substantive contact with the practice. These data will allow the qualitative analysis team to identify practice issues that impact the adoption, implementation, and maintenance of the SMS activities over time, including CTH in the
$\mathrm{CTH}$ and $\mathrm{CTH}+\mathrm{F}$ arms. The facilitator field notes from the improvement team meetings of practices in the $\mathrm{CTH}+\mathrm{F}$ arm will provide especially rich data for assessing the responses to the facilitation intervention in those practices.

The qualitative analysis will be an iterative process, with the investigators going through cycles of reading, summarizing, and re-reading the data. The interpretative analysis will thus proceed iteratively through five phases of qualitative interpretive analysis described by Miller and Crabtree, [105] resulting in a rich interpretive summary of individual practices and themes running across practices.

\section{Dissemination}

Final practice assessments will be shared with each practice at the end of the study period. Core study team members will review all manuscripts and abstracts prior to submission. Results will be reported in peer reviewed publications.

\section{Current status}

Recruitment and data collection are complete as of October, 2017, and data analysis is in progress.

\section{Discussion}

Approximately $70 \%$ of patients presenting to primary care practices in the United States have one or more chronic diseases. Primary care clinicians have a difficult time fitting multiple agenda items into brief patient visits and cannot easily meet the SMS needs of their patients with chronic conditions [106]. Approximately half of patients leave their primary care visit without an understanding of what their doctor told them, [106] and only 9\% of patients report participating in any shared decision-making regarding their chronic condition [107]. In addition, average adherence rates for lifestyle changes are below 10\% [108]. Thus, innovative, time-efficient, and engaging SMS methods need to be developed to assist patients and primary care clinicians and staff. Web-based programs and applications have shown promise for improvement in health behaviors, yet none facilitate patient engagement and shared decision-making between patients and their healthcare team. The use of $\mathrm{CTH}$, with or without practice facilitation to support implementation, should improve SMS for patients with diabetes in primary care practices. This study will provide important information on the implementation of SMS in primary care practices, the effectiveness of an IBCT tool such as Connection to Health, and the use of practice facilitation to assist practices with implementing SMS. 


\section{Abbreviations}

CCM: Chronic Care Model; CTH + F: Connection to Health plus facilitation; $\mathrm{CTH}$ : Connection to Health; IBCT: interactive behavior-change technology; ICC: intraclass correlation; PCMH: patient-centered medical home: PDSA: plan-do-study-act; RE-AIM: reach, effectiveness, adoption, implementation, and maintenance; SMS: self-management support; SMSED: self-management support plus education (arm of the trial); T2DM: type 2 diabetes mellitus

\section{Funding}

Funding for this work was supported by the National Institute of Diabetes and Digestive and Kidney Diseases (NIDDK Award Number 1R18DK096387), 9000 Rockville Pike, Bethesda, MD 20892, Telephone: 1-800-860-8747. This funding source had no role in the design and execution of this study, and will not have any role during analyses, interpretation of the data, or decision to submit results.

\section{Availability of data and materials}

Data generated and analyzed for the current, ongoing study will be available from the corresponding author on reasonable request after completion of the study.

\section{Authors' contributions}

All authors contributed to the preparation of the grant proposal and read and approved the final manuscript. WPD, LF, LMD, and DMH conceived of the study. WPD, LMD, DMH, LF, BMJ, and DHF initiated the study design and BTJ and DHF helped with implementation. WPD and LF are grant holders. LMD provided statistical expertise, conducted the randomization, and is conducting the primary statistical analysis. The core research team (coauthors) had responsibility for protocol preparation and revisions, practice recruitment, intervention development and execution. The practice facilitation group had responsibility for training and practice coaching. The quantitative and qualitative cores, led by LMD and DHF, had responsibility for data collection, management, and verification. The core research team has responsibility for analysis, interpretation, and preparation of manuscripts.

\section{Ethics approval and consent to participate}

Reviewed and approved by the Colorado Multiple Institutional Review Board, Protocol \#12-0645, Final Protocol Version v9-7-2014. Waiver of documented consent was granted. Verbal informed consent was obtained for interviews and consent for other portions of the protocol is not applicable.

\section{Consent for publication}

Not applicable.

\section{Competing interests}

The authors declare that they have no competing interests.

\section{Publisher's Note}

Springer Nature remains neutral with regard to jurisdictional claims in published maps and institutional affiliations.

\section{Author details}

'Department of Family Medicine, University of Colorado School of Medicine, 12631 E. 17th Ave., Mail Stop F496, Aurora, CO 80045-0508, USA.

${ }^{2}$ Department of Family and Community Medicine, University of California, San Francisco, San Francisco, CA, USA.

Received: 24 July 2017 Accepted: 27 June 2018

Published online: 24 July 2018

\section{References}

1. IOM Committee on Quality of Health Care in America. Crossing the quality chasm: a new health system for the 21st century. Washington, DC: National Academy Press; 2001.

2. Wagner EH, Austin BT, Von Korff M. Improving outcomes in chronic illness. Manag Care Q. 1996;4:12-25.

3. Wagner EH, Austin BT, Von Korff M. Organizing care for patients with chronic illness. Millbank Q. 1996;74:511-44.

4. Bodenheimer T, Wagner EH, Grumbach K. Improving primary care for patients with chronic illness. JAMA. 2002;288:1775-9.
5. Bodenheimer T, Wagner EH, Grumback K. Improving primary care for patients with chronic illness: the chronic care model, part 2. JAMA. 2002; 288:1909-14.

6. Berenson RA, Hammons T, Gans DN, Zuckerman S, Merrell K, Underwood WS, Williams AF. A house is not a home: keeping patients at the center of practice redesign. Health Aff (Millwood). 2008;27:1219-30.

7. Grumbach K, Bodenheimer T. A primary care home for Americans: putting the house in order. JAMA. 2002;288:889-93.

8. Riley KM, Glasgow RE, Eakin EG. Resources for health: a social-ecological intervention for supporting self-management of chronic conditions. J Health Psychol. 2001;6:693-705.

9. Glasgow RE, Toobert DJ, Hampson SE. Effects of a brief office-based intervention to facilitate diabetes dietary self-management. Diabetes Care. 1996;19:835-42.

10. Barrera M, Toobert DJ, Angell KL, Glasgow RE, MacKinnon DP. Social support and social-ecological resources as mediators of lifestyle intervention effects for type 2 diabetes. J Health Psychol. 2006:11:483-95.

11. Schillinger D, Handley M, Wang F, Hammer H. Effects of self-management support on structure, process, and outcomes among vulnerable patients with diabetes: a three-arm practical clinical trial. Diabetes Care. 2009;32:559-66.

12. Norris SL, Engelgau MM, Narayan KM. Effectiveness of self-management training in type 2 diabetes. A systematic review of randomized control trials. Diabetes Care. 2001;24:561-87.

13. Tallia AF, Stange KC, McDaniel RR Jr, Aita VA, Miller WL, Crabtree BF. Understanding organizational designs of primary care practices. J Healthc Manag. 2003;48:45-59. discussion 60-41

14. Solberg LI, Brekke ML, Fazio CJ, Fowles J, Jacobsen DN, Kottke TE, Mosser G, O'Connor PJ, Ohnsorg KA, Rolnick SJ. Lessons from experienced guideline implementers: attend to many factors and use multiple strategies. Jt Comm J Qual Improv. 2000;26:171-88.

15. Jaen CR. Successful health information technology implementation requires practice and health care system transformation. Ann Fam Med. 2011:9:388-9.

16. Sittig DF, Ash JS. On the importance of using a multidimensional sociotechnical model to study health information technology. Ann Fam Med. 2011;9:390-1.

17. Glasgow RE, Bull SS, Piette JD, Steiner JF. Interactive behavior change technology. A partial solution to the competing demands of primary care Am J Prev Med. 2004:27:80-7.

18. Glasgow RE. Interactive media for diabetes self-management: issues in maximizing public health impact. Med Decis Mak. 2010;30:745-58.

19. Oenema A, Brug J, Dijkstra A, de Weerdt I, de Vries H. Efficacy and use of an internet-delivered computer-tailored lifestyle intervention, targeting saturated fat intake, physical activity and smoking cessation: a randomized controlled trial. Ann Behav Med. 2008;35:125-35

20. Prochaska JO, Velicer WF, Redding C, Rossi JS, Goldstein M, DePue J, Greene GW, Rossi SR, Sun X, Fava JL, et al. Stage-based expert systems to guide a population of primary care patients to quit smoking, eat healthier, prevent skin cancer, and receive regular mammograms. Prev Med. 2005;41:406-16.

21. Vandelanotte C, De Bourdeaudhuij I, Brug J. Two-year follow-up of sequential and simultaneous interactive computer-tailored interventions for increasing physical activity and decreasing fat intake. Ann Behav Med. 2007:33:213-9.

22. Glasgow RE, Edwards LL, Whitesides H, Carroll N, Sanders TJ, McCray BL. Reach and effectiveness of DVD and in-person diabetes self-management education. Chronic IIIn. 2009:5:243-9.

23. Rabin BA, Glasgow RE. Dissemination and implementation of interactive health communication applications. In: Noar SM, Harrington NG, editors. eHealth applications : promising strategies for health behavior change. New York: Routledge; 2011.

24. Brug J, Oenema A, Campbell M. Past, present, and future of computertailored nutrition education. Am J Clin Nutr. 2003;77:1028S-34S.

25. Tate DF, Jackvony EH, Wing RR. Effects of internet behavioral counseling on weight loss in adults at risk for type 2 diabetes: a randomized trial. JAMA. 2003;289:1833-6.

26. Oenema A, Brug J, Lechner L. Web-based tailored nutrition education: results of a randomized controlled trial. Health Educ Res. 2001;16:647-60.

27. Vandelanotte C, De Bourdeaudhuij I, Brug J. Acceptability and feasibility of an interactive computer-tailored fat intake intervention in Belgium. Health Promot Int. 2004;19:463-70.

28. Wanner M, Martin-Diener E, Braun-Fahrlander C, Bauer G, Martin BW Effectiveness of active-online, an individually tailored physical activity 
intervention, in a real-life setting: randomized controlled trial. J Med Internet Res. 2009;11:e23.

29. Spittaels H, De Bourdeaudhuij I, Brug J, Vandelanotte C. Effectiveness of an online computer-tailored physical activity intervention in a real-life setting. Health Educ Res. 2007;22:385-96.

30. Steele R, Mummery WK, Dwyer T. Using the internet to promote physical activity: a randomized trial of intervention delivery modes. J Phys Act Health. 2007:4:245-60.

31. Strecher VJ, McClure J, Alexander G, Chakraborty B, Nair V, Konkel J, Greene S, Couper M, Carlier C, Wiese C, et al. The role of engagement in a tailored web-based smoking cessation program: randomized controlled trial. J Med Internet Res. 2008;10:e36.

32. Strecher VJ, McClure JB, Alexander GL, Chakraborty B, Nair VN, Konkel JM, Greene SM, Collins LM, Carlier CC, Wiese CJ, et al. Web-based smoking-cessation programs: results of a randomized trial. Am J Prev Med. 2008;34:373-81.

33. Austin, Boren S, Gunlock TL, Krishna S, Kramer TC. Computer-aided diabetes education: a synthesis of randomized controlled trials. AMIA Annu Symp Proc. 2006:51-5.

34. Welch G, Weinger K, Anderson B, Polonsky WH. Responsiveness of the problem areas in diabetes (PAID) questionnaire. Diabet Med. 2003;20:69-72.

35. Bennett GG, Glasgow RE. The delivery of public health interventions via the internet: actualizing their potential. Annu Rev Public Health. 2009;30:273-92.

36. Strecher $\mathrm{V}$. Internet methods for delivering behavioral and health-related interventions (eHealth). Annu Rev Clin Psychol. 2007:3:53-76.

37. Bandura A, editor. Self-efficacy: the exercise of control. New York: W.H. Freeman; 1997.

38. Glasgow RE. A practical model of diabetes management and education. Diabetes Care. 1995:18:117-26.

39. Glasgow RE, Eakin EG. Issues in diabetes self-management. In: Shumaker SA, Schron EB, Ockene JK, McBee WL, editors. The handbook of health behavior change 2nd edition. New York: Springer Publishing Company; 1998. p. 435-61.

40. Glasgow RE, Strycker LA, Toobert DJ, Eakin E. A social-ecologic approach to assessing support for disease self-management: the chronic illness resources survey. J Behav Med. 2000;23:559-83.

41. McLeroy KR, Bibeau D, Steckler A, Glanz K. An ecological perspective on health promotion programs. Health Educ Q. 1988;15:351-77.

42. Stokols D, Allen J, Bellingham RL. The social ecology of health promotion: implications for research and practice. Am J Health Promot. 1996;10:247-51.

43. Battersby M, Von Korff M, Schaefer J, Davis C, Ludman E, Greene SM, Parkerton M, Wagner EH. Twelve evidence-based principles for implementing self-management support in primary care. Jt Comm J Qual Patient Saf. 2010;36:561-70.

44. Daubenmier JJ, Weidner G, Sumner MD, Mendell N, Merritt-Worden T, Studley J, Ornish D. The contribution of changes in diet, exercise, and stress management to changes in coronary risk in women and men in the multisite cardiac lifestyle intervention program. Ann Behav Med. 2007;33:57-68.

45. Ades PA. Cardiac rehabilitation and secondary prevention of coronary heart disease. N Engl J Med. 2001;345:892-902.

46. Brochu M, Poehlman ET, Ades PA. Obesity, body fat distribution, and coronary artery disease. J Cardpulm Rehabil. 2000;20:96-108.

47. Toobert DJ, Glasgow RE. Problem solving and diabetes self-care. J Behav Med. 1991;14:71-86.

48. Baron RJ. Quality improvement with an electronic health record: achievable, but not automatic. Ann Intern Med. 2007;147:549-52.

49. Crosson JC, Etz RS, Wu S, Straus SG, Eisenman D, Bell DS. Meaningful use of electronic prescribing in 5 exemplar primary care practices. Ann Fam Med. 2011;9:392-7.

50. Crosson J, Isaacson N, Lancaster D, McDonald E, Schueth A, DiCicco-Bloom B, Newman J, Wang C, Bell D. Variation in electronic prescribing implementation among twelve ambulatory practices. J Gen Intern Med. 2008;23:364-71

51. Baron RJ, Desnouee E. Practice profile. The struggle to support patients' efforts to change their unhealthy behavior. Health Aff (Millwood). 2010;29: 953-5.

52. Harvey G, Loftus-Hills A, Rycroft-Malone J, Titchen A, Kitson A, McCormack B, Seers K. Getting evidence into practice: the role and function of facilitation. J Adv Nurs. 2002;37:577-88.
53. Nagykaldi Z, Mold JW, Aspy CB. Practice facilitators: a review of the literature. Fam Med. 2005:37:581-8.

54. Goodwin MA, Zyzanski SJ, Zronek S, Ruhe M, Weyer SM, Konrad N, Esola D, Stange KC. A clinical trial of tailored office systems for preventive service delivery. The study to enhance prevention by understanding practice (STEPUP). [see comments]. Am J Prev Med. 2001:21:20-8.

55. Margolis PA, Lannon CM, Stuart JM, Fried BJ, Keyes-Elstein L, Moore DE Jr. Practice based education to improve delivery systems for prevention in primary care: randomised trial. BMJ. 2004;328:388.

56. Stange KC, Goodwin MA, Zyzanski SJ, Dietrich AJ. Sustainability of a practice-individualized preventive service delivery intervention. Am J Prev Med. 2003;25:296-300.

57. Hogg W, Baskerville N, Nykiforuk C, Mallen D. Improved preventive care in family practices with outreach facilitation: understanding success and failure. J Health Serv Res Policy. 2002;7:195-201.

58. Buscaj E, Hall T, Montgomery L, Fernald DH, King J, Deaner N, Dickinson WP. Practice facilitation for PCMH implementation in residency practices. Fam Med. 2016;48:795-800.

59. White DE, Straus SE, Stelfox HT, Holroyd-Leduc JM, Bell CM, Jackson K, Norris $J M$, Flemons WW, Moffatt ME, Forster AJ. What is the value and impact of quality and safety teams? A scoping review. Implement Sci. 2011:6:97.

60. Ivers NM, Halperin IJ, Barnsley J, Grimshaw JM, Shah BR, Tu K, Upshur R, Zwarenstein M. Allocation techniques for balance at baseline in cluster randomized trials: a methodological review. Trials. 2012;13:120.

61. Alexander F, Roberts MM, Lutz W, Hepburn W. Randomisation by cluster and the problem of social class bias. J Epidemiol Community Health. 1989:43:29-36.

62. Shah S, Peat JK, Mazurski EJ, Wang H, Sindhusake D, Bruce C, Henry RL, Gibson PG. Effect of peer led programme for asthma education in adolescents: cluster randomised controlled trial. BMJ. 2001:322:583-5.

63. Carman WF, Elder AG, Wallace LA, McAulay K, Walker A, Murray GD, Stott DJ. Effects of influenza vaccination of health-care workers on mortality of elderly people in long-term care: a randomised controlled trial. Lancet. 2000;355:93-7.

64. Dickinson LM, Beaty B, Fox C, Pace W, Dickinson WP, Emsermann C, Kempe A. Pragmatic cluster randomized trials using covariate constrained randomization: a method for practice-based research networks (PBRNs). J Am Board Fam Med. 2015;28:663-72.

65. Li F, Lokhnygina Y, Murray DM, Heagerty PJ, DeLong ER. An evaluation of constrained randomization for the design and analysis of grouprandomized trials. Stat Med. 2016;35:1565-79.

66. Giraudeau B, Ravaud P. Preventing Bias in cluster randomised trials. PLoS Med. 2009:6:e1000065

67. Puffer S, Torgerson D, Watson J. Evidence for risk of bias in cluster randomised trials: review of recent trials published in three general medical journals. BMJ. 2003;327:785-9.

68. Campbell MK, Elbourne DR, Altman DG. CONSORT statement: extension to cluster randomised trials. BMJ. 2004;328:702-8.

69. Murray D, editor. Design and analysis of group-randomized trials. New York Oxford University Press; 1998

70. Liddy C, wiens M, Hogg W. Methods to achieve high interrater reliability in data collection from primary care medical records. Ann Fam Med. 2011:9:57-62

71. Glasgow RE, Dickinson WP, Fisher L, Christiansen S, Toobert DJ, Bender BG, Dickinson LM, Jortberg B, Estabrooks PA: Patient-Centered Assessment, communication, and Outcomes in the Primary Care Medical Home: Use of RE-AIM to Develop a Multi-Media Facilitation Tool. Implementation Science. In Press.

72. Glasgow RE, McKay HG, Piette JD, Reynolds KD. The RE-AIM framework for evaluating interventions: what can it tell us about approaches to chronic illness management? Patient Educ Couns. 2001;44:119-27.

73. Glasgow RE, Linnan LA. Evaluation of theory-based interventions. In: Glanz K, Rimer BK, Viswanath K, editors. Health Behavior and Health Education: Theory, Research, and Practice 4th ed. San Francisco: Jossey-Bass; 2008. p. 487-508.

74. Gaglio B, Glasgow RE. Evaluation Approaches for Dissemination and Implementation Research. In: Brownson RC, Colditz GA, Proctor EK, editors. Dissemination and implementation research in health : translating science to practice. Oxford: Oxford University Press; 2010.

75. Belza B, Toobert DJ, Glasgow RE. RE-AIM for program planning: overview and applications: Center for Healthy Aging Issue Brief. VA: National Council on Aging in Arlington; 2007. 
76. Toobert DJ. RE-AIM: application to AoA evidence-based demonstration projects. In: 3rd annual Agency on Aging grantees conference. Washington, D.C. p. 2006

77. Reach Effectiveness Adoption Implementation Maintenance (RE-AIM) [www re-aim.org]. Accessed 8 July 2018.

78. Glasgow R, Emmons KM. The public health need for patient-reported measures and health behaviors in electronic health records: a policy statement of the Society of Behavioral Medicine. Translational Behav Med. 2011;1:108-9.

79. Paxton AE, Strycker LA, Toobert DJ, Ammerman AS, Glasgow RE. Starting the conversation performance of a brief dietary assessment and intervention tool for health professionals. Am J Prev Med. 2011;40:67-71.

80. Toobert DJ, Hampson SE, Glasgow RE. The summary of diabetes self-care activities measure: results from 7 studies and a revised scale. Diabetes Care. 2000;23:943-50

81. Jilcott SB, Keyserling TC, Samuel-Hodge CD, Johnston LF, Gross MD, Ammerman AS. Validation of a brief dietary assessment to guide counseling for cardiovascular disease risk reduction in an underserved population. J Am Diet Assoc. 2007;107:246-55.

82. Moshfegh A, Goldman J, Ahuja J, Rhodes D, LaComb R: What We Eat in America, NHANES 2005-2006: Usual nutrient intakes from food and water compared to 1997 Dietary Reference Intakes for Vitamin D, Calcium, Phosphorous, and Magnesium. Beltsville: U.S. Department of Agriculture, Agricultural Research Service; 2009.

83. Craig $C L$, Marshall AL, Sjostrom M, Bauman AE, Booth ML, Ainsworth BE, Pratt M, Ekelund U, Yngve A, Sallis JF, Oja P. International physical activity questionnaire: 12-country reliability and validity. Med Sci Sports Exerc. 2003; 35:1381-95.

84. Bender BG, Bartlett SJ, Rand CS, Turner C, Wamboldt FS, Zhang L. Impact of interview mode on accuracy of child and parent report of adherence with asthma-controller medication. Pediatrics. 2007:120:e471-7.

85. Bender BG, Rankin A, Tran ZV, Wamboldt FS. Brief-interval telephone surveys of medication adherence and asthma symptoms in the childhood asthma management program continuation study. Ann Allergy Asthma Immunol. 2008:101:382-6.

86. Horne R, Weinman J. Patients' beliefs about prescribed medicines and their role in adherence to treatment in chronic physical illness. J Psychosom Res. 1999:47:555-67.

87. Dawson DA, Grant BF, Li TK. Quantifying the risks associated with exceeding recommended drinking limits. Alcohol Clin Exp Res. 2005;29:902-8.

88. Helping patients who drink too much: A clinician's guide. [http://pubs.niaaa. nih.gov/publications/Practitioner/CliniciansGuide2005/clinicians_guide.htm]. Accessed 8 July 2018.

89. Ory MG, Jordan PJ, Bazzarre T. The behavior change consortium: setting the stage for a new century of health behavior-change research. Health Educ Res. 2002;17:500-11.

90. Behavioral Risk Factor Surveillance System [http://www.cdc.gov/brfss/ questionnaires/pdf-ques/2004brfss.pdf]. Accessed 8 July 2018.

91. Kroenke K, Spitzer RL, Williams JB, Lowe B. An ultra-brief screening scale for anxiety and depression: the PHQ-4. Psychosomatics. 2009;50:613-21.

92. Spitzer RL, Kroenke K, Williams JB, Lowe B. A brief measure for assessing generalized anxiety disorder: the GAD-7. Arch Intern Med. 2006;166:1092-7.

93. Fisher L, Skaff MM, Mullan JT, Arean P, Glasgow R, Masharani U. A longitudinal study of affective and anxiety disorders, depressive affect and diabetes distress in adults with type 2 diabetes. Diabet Med. 2008;25:1096-101.

94. Polonsky WH, Fisher L, Earles J, Dudl RJ, Lees J, Mullan J, Jackson RA Assessing psychosocial distress in diabetes: development of the diabetes distress scale. Diabetes Care. 2005;28:626-31.

95. Raudenbush SW, Liu X. Statistical power and optimal design for multisite randomized trials. Psychol Methods. 2000;5:199-213.

96. Hedeker D, Gibbons RD, Waternaux C. Sample size estimation for longitudinal designs with attrition. J Educ Behav Stat. 1999;24:70-93.

97. Dempster AP, Laird NM, Rubin DB: Maximum likelihood estimation from incomplete data via the EM algorithm. J R Stat Soc 1977;Series B:1-38.

98. Little RJA, Rubin DB. Statistical analysis with missing data. New York: Wiley; 1987

99. Fairclough $D$, editor. Design and analysis of quality of life studies in clinical trials. Boca Raton: Chapman \& Hall/CRC; 2002.

100. Diggle P, Kenward MG. Informative drop-out in longitudinal data-analysis. J R Stat Soc Ser C Appl Stat. 1994;43:49-93.

101. Littell R, Milliken GA, Stroup WW, Wolfinger RD, editors. SAS System for Mixed Models. Cary: SAS Institute Inc; 1996.
102. Hedeker D, Gibbons RD. Longitudinal Data Analysis. Hoboken, New Jersey: Wiley; 2006

103. Raman R, Hedeker D. A mixed-effects regression model for three-level ordinal response data. Stat Med. 2005:24:3331-45.

104. Bryk AS, Raudenbush SW, editors. Hierarchical Linear Models: Applications and Data Analysis Methods., Second edition. Newbury Park: Sage Publications; 2000

105. Miller WL, Crabtree BF. The dance of interpretation. In: Crabtree BF, Miller WL editors. 2nd edition. Thousand Oaks: Sage Publications, Inc; 1999. p. 127-43.

106. Vale MJ, Jelinek MV, Best JD, Dart AM, Grigg LE, Hare DL, Ho BP, Newman RW, JJ MN, Group CS. Coaching patients On Achieving Cardiovascular Health (COACH): a multicenter randomized trial in patients with coronary heart disease. Arch Intern Med. 2003;163:2775-83.

107. Holmes-Rovner M, Stommel M, Corser WD, Olomu A, Holtrop JS, Siddiqi A, Dunn SL. Does outpatient telephone coaching add to hospital quality improvement following hospitalization for acute coronary syndrome? J Gen Intern Med. 2008;23:1464-70.

108. Whittemore R, Melkus GD, Sullivan A, Grey M. A nurse-coaching intervention for women with type 2 diabetes. Diabetes Educ. 2004;30:795-804

\section{Ready to submit your research? Choose BMC and benefit from:}

- fast, convenient online submission

- thorough peer review by experienced researchers in your field

- rapid publication on acceptance

- support for research data, including large and complex data types

- gold Open Access which fosters wider collaboration and increased citations

- maximum visibility for your research: over $100 \mathrm{M}$ website views per year

At BMC, research is always in progress.

Learn more biomedcentral.com/submissions 